\title{
Highly Selective Phosgene-Free Carbamoylation of Aniline by Dimethyl Carbonate under Continuous-Flow Conditions
}

\author{
Sandra Grego, Fabio Aricò, and Pietro Tundo* \\ Department of Environmental Sciences, Informatics and Statistics, Ca' Foscari University of Venice, Dorsoduro 2137, 30123 Venezia, \\ Italia
}

ABSTRACT: Over the last 20 years organic carbamates have found numerous applications in pesticides, fungicides, herbicides, dyes, pharmaceuticals, cosmetics, and as protecting groups and intermediates for polyurethane synthesis. Recently, in order to avoid phosgene-based synthesis of carbamates, many environmentally benign and alternative pathways have been investigated. However, few examples of carbamoylation of aniline in continuous-flow apparatus have been reported. In this work, we report a high-yielding, dimethyl carbonate (DMC)-mediated carbamoylation of aniline in a fixed-bed continuously fed reactor employing basic zinc carbonate as catalyst. Several variables of the system have been investigated (i.e. molar ratio of reagents , flow rate, and reaction temperature) to optimize the operating conditions of the system.

\section{INTRODUCTION}

Organic carbamates are industrially relevant compounds which, over the last 20 years, have found numerous applications in pesticides, fungicides, herbicides, dyes, pharmaceuticals, cosmetics, and as protecting groups. ${ }^{1}$ Carbamates can also be readily converted into isocyanates for polyurethane synthesis via thermodecomposition. ${ }^{2}$

Industrially, these compounds are synthesised predominantly via phosgene routes, i.e. by reacting the parent amine with chloroformate. ${ }^{3}$ Due to the toxicity of this process, in recent years many environmentally benign and alternative pathways have been investigated. Some examples of this are oxidative carbonylation of amines, reductive carbonylation of aromatic nitro compounds, methoxycarbonylation via carbonate chemistry and reaction of urea with symmetrical carbonates. ${ }^{3,4}$ The latter synthesis, although very efficient, can only be used when the two components (urea and carbonate) are either both aliphatic or aromatic, limiting the possible number of accessible products. ${ }^{5}$

Among the above-mentioned reactions, the carbamoylation of aniline via dimethyl carbonate (DMC) chemistry is probably the most promising phosgene-free route to carbamates.

In fact, short-chain dialkyl carbonates (DACs) and in particular DMC are renowned for possessing properties of low toxicity and high biodegradability, which make them true green solvents and reagents. ${ }^{6}$ Furthermore, DMC has been used as an efficient eco-sustainable substitute of the most common methoxycarbonylating and methylating agents such as phosgene, methyl halides, or dimethylsulfate showing high selectivity with different monodentate and bidentate nucleophiles. ${ }^{7}$

Over the last 10 years, reactions between amines and symmetrical DACs have been investigated, resulting in the highly selective synthesis of monoalkyl, dialkyl derivatives and in some cases of the related carbamates. ${ }^{8}$ However, in most cases, the synthesis of carbamates results in poor atom economy due to the presence of the corresponding alcohol byproduct.
Recently, several examples of carbamoylation of aniline, ${ }^{9}$ $4,4^{\prime}$-methylenedibenzenamine ${ }^{10}$ (for the synthesis of methylene diphenyl diisocyanate, MDI) and 2,4-diaminotoluene ${ }^{11}$ (for the synthesis of toluene diisocyanate TDI) have been reported by DMC chemistry in the presence of either homogeneous or supported catalysts. An example is the efficient carbamoylation of 2,4-diaminotoluene (DAT) by gold-catalyzed phosgene-free synthesis. This approach is particularly interesting as it can be extended to a one-pot process which, starting from 2,4dinitrotoluene, leads directly to the polyurethane precursor TDI. $^{12}$

Several syntheses of carbamates involving the use of DACs have also been extensively investigated. ${ }^{13}$

Furthermore, our group has recently reported a comprehensive study on the synthesis of methyl phenylcarbamate from aniline and DMC in the presence of homogeneous, supported heterogeneous, and heterogeneous catalysts in batch conditions. A selection of homogeneous catalysts has been studied, and the reactivities have been compared to that of zinc acetate, a catalyst extensively used for this reaction. The best homogeneous catalysts were then supported on silica or alumina and the resulting heterogeneous supported catalysts investigated for the carbamoylation of aniline. Several heterogeneous catalysts have also been investigated. Among them, basic zinc carbonate was shown to be the best catalyst, giving almost quantitative conversion and selectivity for the methyl phenylcarbamate. Zinc carbonate also proved to be recyclable, once recovered from the reaction mixture and calcinated. $^{14}$

It is noteworthy that most of the above-mentioned reactions have been carried out in batch conditions. Few examples of carbamoylation in a continuous-flow apparatus have been reported, i.e., a semi-continuous process for the synthesis of methyl carbamate from urea and methanol ${ }^{15}$ and a gas-solid oxidative carbonylation reaction of aniline in a semibatched

Received: January 8, 2013

Published: March 13, 2013 
fixed-bed reactor. ${ }^{16}$ The latter process employs a $\mathrm{NaI}-\mathrm{Pd} / \mathrm{C}$ catalyst, and the synthesis proceeds in only $2 \mathrm{~h}$ with $80 \%$ of aniline conversion and 74\% carbamate yield.

Recently, an example of a high-yielding carbamoylation of aromatic anilines, employing a tetranuclear cluster $\mathrm{Zn}_{4} \mathrm{O}(\mathrm{OAc})_{6}$ as catalyst, has been reported. However, all the reactions have been performed in an autoclave, and the use of a continuousflow apparatus has only been mentioned. ${ }^{17}$

Herein we report a high-yielding DMC-mediated carbamoylation of aniline in a fixed-bed, continuously fed reactor (see Scheme 1). Basic zinc carbonate was selected as catalyst since it

Scheme 1. Carbamoylation of aniline

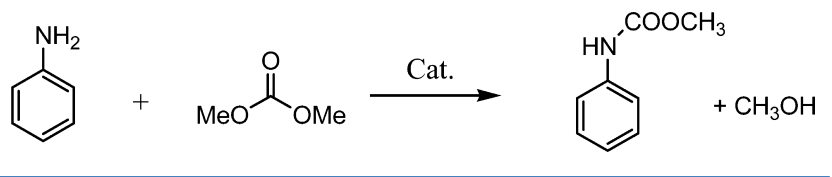

was found to be the most efficient during our batch trials. Several variables have been investigated, i.e. molar ratio of the reagents, flow rate, reaction temperature, volume of the reactor, and catalysis stability in order to optimize the operating conditions of the system.

\section{RESULTS AND DISCUSSION}

Variation of Aniline/DMC Ratio. In a first set of experiments the influence of the aniline/DMC molar ratio on the selectivity of the carbamoylation reaction was investigated. In Table 1 are summarized the conversion and selectivity of the

Table 1. Variation of the aniline/DMC ratio in the reaction of aniline with DMC under continuous-flow conditions ${ }^{a}$

\begin{tabular}{|c|c|c|c|c|c|c|}
\hline \multirow[b]{2}{*}{ no. } & \multirow[b]{2}{*}{$\begin{array}{c}\text { aniline/ } \\
\text { DMC } \\
\text { (mol ratio) }\end{array}$} & \multirow[b]{2}{*}{$\begin{array}{c}\text { temp. } \\
\left({ }^{\circ} \mathrm{C}\right)\end{array}$} & \multirow[b]{2}{*}{$\begin{array}{l}\text { conv. } \\
(\%)\end{array}$} & \multicolumn{2}{|c|}{ selectivity $(\%)^{b}$} & \multirow{2}{*}{$\begin{array}{l}\text { production } \\
\text { rate } b / h \\
\text { (carbamate } \\
\quad+\text { urea) }\end{array}$} \\
\hline & & & & carbamate & $\begin{array}{c}\text { carbamate } \\
\text { + urea }\end{array}$ & \\
\hline 1 & $1 / 20$ & 200 & 99 & 96 & 96 & 0.24 \\
\hline 2 & $1 / 10$ & 200 & 97 & 95 & 96 & 0.45 \\
\hline 3 & $1 / 7$ & 200 & 96 & 93 & 94 & 0.63 \\
\hline 4 & $1 / 5$ & 200 & 92 & 91 & 93 & 0.75 \\
\hline 5 & $1 / 3$ & 200 & 90 & 88 & 90 & 0.98 \\
\hline
\end{tabular}

${ }^{a}$ Flow rate was $0.05 \mathrm{~mL} / \mathrm{min} .{ }^{b}$ Selectivity and production rates have been calculated by HPLC and ${ }^{1} \mathrm{H}$ NMR analysis.

experiments conducted. The amount of carbamate and urea produced by the system has been calculated so as to compare the grams of products synthesised in the time unit.

In the first trial the continuously fed reactor $(4.15 \mathrm{~mL}$ volume), charged with zinc carbonate catalyst, was heated at $200{ }^{\circ} \mathrm{C}$ and the reagents flow rate was set to $0.05 \mathrm{~mL} / \mathrm{min}$. A mixture of aniline/DMC in $1 / 20$ molar ratio was fed into the system. HPLC and NMR analysis of the resulting mixture indicated a conversion of $99 \%$ and a selectivity of $96 \%$ (entry 1, Table 1). Decreasing the aniline/DMC molar ratio from $1 / 20$ to $1 / 10$ (Table 1 , entries 1 and 2 , respectively) did not seem to effect the conversion or the selectivity of the reaction that, in any case, remained almost quantitative. When the molar ratio was further diminished (Table 1, entries 3-5 ) both conversion and selectivity slightly decreased although they consistently remained above $90 \%$ even when an aniline/DMC molar ratio of $1 / 3$ was used.
In all the experiments carried out, diphenyl urea was the main byproduct formed. This compound can be easily converted into the methyl phenylcarbamate by transesterification reaction with methanol or $\mathrm{DMC} ;{ }^{18}$ thus, its selectivity has been considered in the calculation of the continuously fed reactor production rate.

Considering the economical aspect of an eventual industrial process (i.e. lowest amount of reagents possible) and best conversion and selectivity, the results achieved with an aniline/ DMC molar ratio of $1 / 10$ (entry 2 , Table 1 ) represent the most convenient reaction conditions.

Variation of Flow Rate. A set of trials was then conducted using the best aniline/DMC molar ratio found $(1 / 10)$ at 200 ${ }^{\circ} \mathrm{C}$ and selecting different flow rates of the reagents (entries $1-$ 4, Table 2).

Table 2. Variation of flow rate in the reaction of aniline with DMC under continuous-flow conditions

\begin{tabular}{|c|c|c|c|c|c|c|}
\hline \multirow[b]{2}{*}{ no. } & \multirow[b]{2}{*}{$\begin{array}{l}\text { flow rate } \\
(\mathrm{mL} / \mathrm{min})\end{array}$} & \multirow[b]{2}{*}{$\begin{array}{c}\text { temp. } \\
\left({ }^{\circ} \mathrm{C}\right)\end{array}$} & \multirow[b]{2}{*}{$\begin{array}{c}\text { conv. } \\
(\%)\end{array}$} & \multicolumn{2}{|c|}{ selectivity (\%) } & \multirow{2}{*}{$\begin{array}{l}\text { production } \\
\text { rate } \mathrm{g} / \mathrm{h} \\
\text { (carbamate } \\
\quad+\text { urea) }\end{array}$} \\
\hline & & & & carbamate & $\begin{array}{l}\text { carbamate } \\
\quad+\text { urea }\end{array}$ & \\
\hline 1 & 0.03 & 200 & 98 & 93 & 94 & 0.27 \\
\hline 2 & 0.05 & 200 & 98 & 94 & 95 & 0.45 \\
\hline 3 & 0.10 & 200 & 98 & 97 & 98 & 0.93 \\
\hline 4 & 0.15 & 200 & 89 & 96 & 98 & 1.27 \\
\hline
\end{tabular}

It is evident that increasing the flow rate from $0.03 \mathrm{~mL} / \mathrm{min}$ to $0.10 \mathrm{~mL} / \mathrm{min}$ did not result in any significant difference of conversion and/or selectivity of the methyl phenylcarbamate that forms in almost quantitative yield. The best results were achieved at $0.10 \mathrm{~mL} / \mathrm{min}$ flow rate with $98 \%$ conversion of the substrate and $97 \%$ selectivity of the carbamate.

On the other hand, when the flow rate of the aniline/DMC mixture was further increased to $0.15 \mathrm{~mL} / \mathrm{min}$, the conversion started to decrease (89\%) as the residence time on the catalytic bed was too short to allow full conversion (entry 4, Table 2).

In consideration of the experiments carried out, the optimal flow rate of the system for the carbamoylation of aniline at 200 ${ }^{\circ} \mathrm{C}$ (aniline/DMC ratio $1 / 10$ ) is $0.10 \mathrm{~mL} / \mathrm{min}$ (entry 3, Table 2).

Variation of Temperature. The effect of temperature on the carbamoylation of aniline in the fixed bed, continuous-flow reactor was then investigated.

Three sets of experiments were considered. In a first set of trials a solution of aniline/DMC in a $1 / 20$ molar ratio was pumped at $0.05 \mathrm{~mL} / \mathrm{min}$ flow rate through the reactor charged with the zinc carbonate at different temperatures, i.e., 160-200 ${ }^{\circ} \mathrm{C}$ (entries 1-3, Table 3). In all cases the conversion ranged from almost quantitative $(\geq 94 \%)$ to quantitative for the reaction at $200{ }^{\circ} \mathrm{C}$ (entry 3 , Table 3$)$.

In a second set of experiments an aniline/DMC molar ratio of $1 / 10$ (entries 4-6, Table 3) was employed, and the temperatures were varied from 160 to $200{ }^{\circ} \mathrm{C}$. In this case the best results in terms of conversion and selectivity were obtained when the reaction was performed at $200{ }^{\circ} \mathrm{C}$ (entry 6, Table 3). In fact, when the reactor temperature was set at $160{ }^{\circ} \mathrm{C}$, it resulted in an evident lower conversion (63\%) although the selectivity remained almost unaltered (entry 4, Table 3 ).

Finally, a faster flow rate of the reagents was utilised at different temperatures, i.e. $0.10 \mathrm{~mL} / \mathrm{min}$ at $180-200{ }^{\circ} \mathrm{C}$ 
Table 3. Variation of temperature in the reaction of aniline with DMC under continuous-flow conditions ${ }^{a}$

\begin{tabular}{|c|c|c|c|c|c|c|}
\hline \multirow[b]{2}{*}{ no. } & \multirow[b]{2}{*}{ aniline/DMC (mol ratio) } & \multirow[b]{2}{*}{ temp. $\left({ }^{\circ} \mathrm{C}\right)$} & \multirow[b]{2}{*}{ conv. (\%) } & \multicolumn{2}{|c|}{ selectivity $(\%)^{b}$} & \multirow[b]{2}{*}{ production rate $\mathrm{g} / \mathrm{h}$ (carbamate + urea $)$} \\
\hline & & & & carbamate & carbamate + urea & \\
\hline 1 & $1 / 20$ & 160 & 94 & 99 & 99 & 0.24 \\
\hline 2 & $1 / 20$ & 180 & 99 & 95 & 95 & 0.24 \\
\hline $3^{b}$ & $1 / 20$ & 200 & 99 & 96 & 96 & 0.24 \\
\hline 4 & $1 / 10$ & 160 & 63 & 92 & 95 & 0.29 \\
\hline 5 & $1 / 10$ & 180 & 95 & 92 & 94 & 0.43 \\
\hline $6^{b}$ & $1 / 10$ & 200 & 98 & 94 & 95 & 0.45 \\
\hline $7^{c}$ & $1 / 10$ & 180 & 89 & 94 & 95 & 0.83 \\
\hline $8^{c, d}$ & $1 / 10$ & 200 & 98 & 97 & 98 & 0.93 \\
\hline $9^{c}$ & $1 / 10$ & 210 & 97 & 96 & 97 & 0.91 \\
\hline
\end{tabular}

${ }^{a}$ Flow rate $0.05 \mathrm{~mL} / \mathrm{min} .{ }^{b}$ Result from Table 1, reported here for comparison. ${ }^{c}$ Flow rate of $0.10 \mathrm{~mL} / \mathrm{min} .{ }^{d}$ Result from Table 2, reported here for comparison.

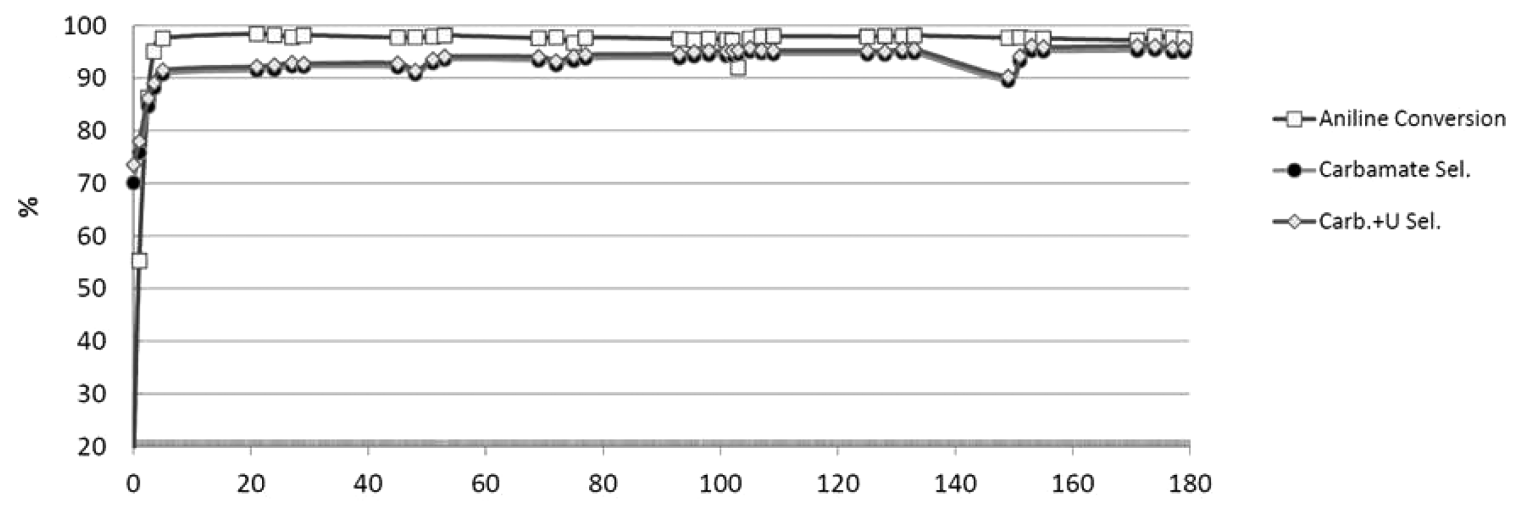

Time (h)

Figure 1. Conversion and selectivity percentage vs time in the reaction of aniline with DMC under continuous-flow conditions.

Table 4. Variation of volume of the fixed-bed, continuous-flow reactor used for carbamoylation of aniline $e^{a}$

\begin{tabular}{|c|c|c|c|c|c|c|}
\hline \multirow[b]{2}{*}{ no. } & \multirow[b]{2}{*}{ reactor vol. $(\mathrm{mL})$} & \multirow[b]{2}{*}{ flow $(\mathrm{mL} / \mathrm{min})$} & \multirow[b]{2}{*}{ conv. (\%) } & \multicolumn{2}{|c|}{ selectivity (\%) } & \multirow[b]{2}{*}{ production rateg/h (carbamate + urea $)$} \\
\hline & & & & carbamate & carbamate + urea & \\
\hline $1^{b}$ & 4.15 & 0.10 & 98 & 97 & 98 & 0.93 \\
\hline 2 & 10.73 & 0.25 & 97 & 96 & 97 & 2.23 \\
\hline
\end{tabular}

${ }^{a}$ Aniline/DMC ratio $1 / 10$, temperature $200{ }^{\circ} \mathrm{C} .{ }^{b}$ Result from Table 2 (entry 3), reported here for comparison.

(entries 7-8, Table 3). Analysis of the product mixture showed that the best result was achieved when the reaction was performed at $200{ }^{\circ} \mathrm{C}$, i.e. $98 \%$ conversion and $97 \%$ selectivity (entry 8 , Table 3$)$. Operating at higher temperature $\left(210{ }^{\circ} \mathrm{C}\right)$ did not improve the outcome of the reaction (entry 9 , Table 3 ).

This set of experiments confirms the result already reported in Table 2 (entry 3); in fact the best results were achieved when the reaction was performed using an aniline/DMC ratio of $1 /$ 10 at $200{ }^{\circ} \mathrm{C}$ and a flow rate of $0.10 \mathrm{~mL} / \mathrm{min}$ (entry 8, Table 3 ).

Catalyst Performance vs Time. The efficiency of the catalyst over time $(180 \mathrm{~h})$ was considered with the results highlighted in Figure 1. In the experiment an aniline/DMC solution $(1 / 10$ molar ratio) was injected at $0.05 \mathrm{~mL} / \mathrm{min}$ into the reactor set at $200{ }^{\circ} \mathrm{C}$.

Samples were collected over time, showing that conversion and selectivity were in any case above $90 \%$ for the entire duration of the trial. It is noteworthy that the performance of the catalyst appeared to be slightly improved after 60-70 h. Furthermore, when the experiment was stopped (at $48 \mathrm{~h}, 103$ h, and 149 h, Figure 1) and restarted the following day, the activity of the catalyst remained unaltered as the carbamoylation of aniline proceeded in high conversion and selectivity toward the methyl phenylcarbamate.

During the reaction time, $\sim 60 \mathrm{~g}$ of aniline was fed into the reactor and was converted into the related carbamate using an overall amount of $2.48 \mathrm{~g}$ of catalyst, which was still active at the end of the experiment.

Furthermore the amount of zinc carbonate present in the product mixture was measured using atomic absorption spectroscopy analysis. Results indicated that only $0.8 \mathrm{mg}$ of $\mathrm{Zn} / \mathrm{L}$ was present in the solution, demonstrating that the catalyst is stable in the reaction bed and that it is suitable for use in a long-term continuous process.

Variation of Reactor Volume. The effect of the reactor volume was also evaluated. The continuously fed reactor, employed for all of the above-reported trials, had a volume of $4.15 \mathrm{~mL}$. For this experiment, a bigger reactor with a capacity of $10.73 \mathrm{~mL}$ was built up in order to evaluate the possibility to scale up the process. In this new reactor, both the amount of the catalyst and the flow rate were increased ( 2.5 times) in 
order to maintain the same residence time of the smaller reactor $(\sim 35 \mathrm{~min})$. As a result, both conversion and selectivity were consistent with the results thus far achieved (entries 1-2, Table 4).

This experiment proves that the reaction can easily be scaled up using bigger reactors without affecting the conversion and selectivity of the carbamoylation of the aniline.

\section{CONCLUSION}

The direct carbamoylation of aniline in a fixed-bed, continuously fed reactor charged with basic zinc carbonate has been reported.

Results collected demonstrated that, in this continuous-flow system, zinc carbonate performs efficiently for the DMCmediated synthesis of methyl phenylcarbamate, leading to an almost quantitative conversion of the reagent and high selectivity of the carbamate.

Several reaction conditions were investigated, i.e. aniline/ DMC molar ratio, flow rate, temperature, reactor volume, and efficiency of the catalyst vs time. The optimum conditions found for a reactor with a capacity of $4.15 \mathrm{~mL}$ were an aniline/ DMC ratio of $1 / 10$, temperature of $200{ }^{\circ} \mathrm{C}$, and a flow rate of $0.10 \mathrm{~mL} / \mathrm{min}$, resulting in $98 \%$ conversion and $97 \%$ selectivity.

The carbamoylation reaction was also conducted on a larger scale, employing a reactor with double the capacity $(10.73 \mathrm{~mL})$, achieving similar results in terms of conversion and selectivity.

Finally, the stability of the catalyst was also taken into account, performing the reaction at $200{ }^{\circ} \mathrm{C}$ for a total of $180 \mathrm{~h}$. The catalyst gave efficient conversion and selectivity throughout, without showing any loss of activity. Furthermore, negligible leaching of the zinc carbonate was observed.

\section{EXPERIMENTAL SECTION}

All reactions were performed, employing DMC purchased by Sigma Aldrich dried on 4 A molecular sieves.

Aniline and basic zinc carbonate were purchased from Sigma Aldrich and used without any further purification. Aniline, methyl phenylcarbamate, and diphenylurea concentrations were analyzed by HPLC-UV using nitrobenzene as internal standard. The HPLC response factor was calculated using a standard mixture of methyl phenylcarbamate $(87.3 \% \mathrm{~mol})$ and $\mathrm{N}$-methyl aniline $(12.7 \% \mathrm{~mol})$. The standard mixture was prepared, quantified by ${ }^{1} \mathrm{H}$ NMR and HPLC analysis.

The fixed-bed, continuous-flow reactor used for the reactions consisted of a stainless steel tube $(4.15 \mathrm{~mL}$ capacity, $4.6 \mathrm{~mm}$. id, length $250 \mathrm{~mm}$ ) thermostatted with a coiled heating band (Figure 2). Zinc carbonate was charged into the reactor and packed manually. The aniline/DMC solution was fed by a Jasco 880 PU HPLC pump. Products formed were cooled by a condenser and collected via a proportional relief valve, set at $p$ $=15$ bar.

The production rates of the system have been calculated as follows:

$$
\begin{aligned}
\text { aniline }(\text { equiv } / \mathrm{h})= & {[\% \text { aniline } \times \text { flow rate }(\mathrm{mL} / \mathrm{min}) \times 60} \\
& \times \text { density of the mixture }] / \mathrm{MW} \text { aniline }
\end{aligned}
$$

mol equiv (carb. + urea) (equiv/h)

$$
=\text { aniline }(\text { equiv } / \mathrm{h}) \times \% \text { conversion } \times \% \text { selectivity }
$$

$$
\text { grams }(\text { carb. }+ \text { urea } / \mathrm{h})=\text { mol equiv }(\text { carb. }+ \text { urea }) \times M W
$$

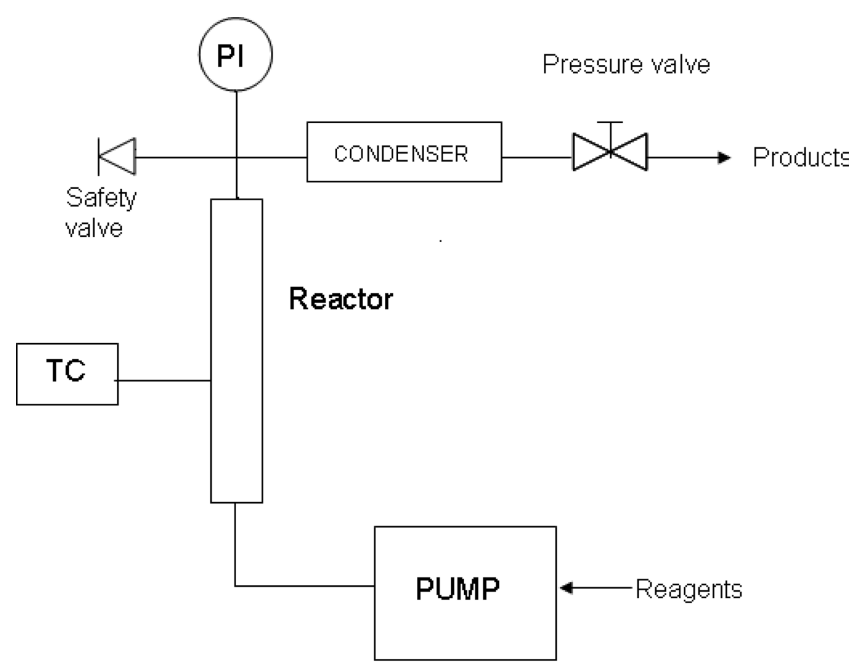

Figure 2. Fixed-bed, continuous-flow reactor used for the experiments.

\section{AUTHOR INFORMATION}

\section{Corresponding Author}

*Tel.: (+39) 041234 8642. Fax: (+39) 041234 8620. E-mail: tundop@unive.it.

\section{Notes}

The authors declare no competing financial interest.

\section{ACKNOWLEDGMENTS}

We thank Renato Paludetto for his contribution and Dow Italia S.r.l. Porto Marghera for support and funding of this work.

\section{REFERENCES}

(1) (a) Tai-Teh, W.; Huang, J.; Arrington, N.; Dill, G. J. J. Agric. Food Chem. 1987, 35, 817. (b) Rivetti, F.; Romano, U.; Sasselli, M. U.S. Patent 4,514,339, 1985. (c) Kato, T.; Suzuki, K.; Takahashi, J.; Kamoshita, K. J. Pesticide Sci. 1943, 9, 489. (d) Aresta, M.; Quaranta, E. Chem. Technol. 1997, 3, 32. (e) Greene, T.; Wuts, P. Protective Groups in Organic Synthesis, 3rd ed.; Wiley: New York, 1998.

(2) (a) Okuda, S. JP 57158746, 1983; Chem. Abstr. 1983, 98, 144386b;(b) Okuda, S. JP 57158747, 1983; Chem. Abstr. 1983, 98, 160402j. (c) Yagii, T. U.S. Patent 5,789,614, 1998; (d) Gerhard, L. German Patent DE 19541384, 1997.

(3) (a) Babad, H.; Zieler, A. Chem. Rev. 1973, 73, 75. (b) Eckert, H.; Foster, B. Angew. Chem., Int. Ed. Engl. 1987, 26, 894. (c) Costarca, L.; Delogu, P.; Nardelli, A.; Sunjic, V. Synthesis 1996, 5, 553. (d) Cotarca, L.; Ecket, H. Phosgenations: A Handbook; Wiley-VCH Verlag GmbH \& Co.: Weinheim; Cambridge, 2003.

(4) (a) Aresta, M.; Giannoccaro, P.; Tommasi, I. J. Organomet. Chem. 1994, 476, 13. (b) Valli, V.; Alper, H. J. Org. Chem. 1995, 60, 257. (c) Butler, D.; Alper, H. Chem. Commun. 1998, 2575. (d) Yoshida, M.; Hara, N.; Okuyama, S. Chem. Commun. 2000, 151. (e) (PhilippsUniversität Marburg). WO/2006/131381 A1, 2006; (f) Ragaini, F. Dalton Trans. 2009, 6251.

(5) (a) Gupte, S.; Shivarkar, A. Chem. Commun. 2001, 2620. (b) Shivarkar, A. B.; Gupte, S. P.; Chaudhari, P. V. J. Mol. Catal. A: Chem. 2004, 223, 85.

(6) (a) Tundo, P.; Bressanello, S.; Loris, A.; Sathicq, G. Pure Appl. Chem. 2005, 77, 1719. (b) Aricò, F.; Tundo, P.; Maranzana, A.; Tonachini, G. ChemSusChem 2012, 5, 1578. (c) Tundo, P.; Memoli, S.; Hérault, D.; Hill, K. Green Chem. 2004, 6, 609. (d) Tundo, P.; Aricò, F.; Rosamilia, A. E.; Memoli, S. Green Chem. 2008, 10, 1181. (e) Tundo, P.; Aricò, F.; Gauthier, G.; Rossi, L.; Rosamilia, A. E.; Bevinakatti, H. S.; Sievert, R. L.; Newman, C. P. ChemSusChem 2010, 3, 566. (f) Rosamilia, A. E.; Aricò, F.; Tundo, P. J. Phys. Chem. B 2008, 112,14525 . 
(7) (a) Aricò, F.; Toniolo, U.; Tundo, P. Green Chem. 2012, 14, 58. (b) Tundo, P.; Aricò, F.; Gauthier, G.; Baldacci, A. C. R. Chim. 2011, 14, 652. (c) Rosamilia, A. E.; Aricò, F.; Tundo, P. J. Org. Chem. 2008, 73, 1559. (d) McElroy, C. R.; Aricò, F.; Tundo, P. Synlett 2012, 23, 1809.

(8) (a) Dhakshinamoorthy, A.; Alvaro, M.; Garcia, H. Appl. Catal., A 2010, 378, 19. (b) Gooden, P. N.; Bourne, R. A.; Parrott, A. J.; Irvine, D. J.; Poliakoff, M.; Bevinakatti, H. S. Org. Process Res. Dev. 2010, 14, 411. (c) Distaso, M.; Quaranta, E. J. Catal. 2008, 253, 278. (d) Zhou, H.; Shi, F.; Tian, X.; Ahang, Q.; Deng, Y. J. Mol. Catal. A: Chem. 2007, 271, 89. (e) Curini, M.; Epifano, F.; Maltese, F.; Rosati, O. Tetrahedron Lett. 2002, 43, 4895. (f) Sima, T.; Guo, S.; Shi, F.; Deng, Y. Tetrahedron Lett. 2002, 43, 8145.

(9) Fu, O. J. Mol. Catal. 1994, 91, 399.

(10) Zhao, X.; Wang, Y.; Wang, S.; Yang, H.; Zhang, J. Ind. Eng. Chem. Res. 2002, 41, 5139.

(11) Wang, Y.; Zhao, X.; Li, F.; Wang, S.; Zhang, J. J. Chem. Technol. Biotechnol. 2001, 76, 857.

(12) Juarez, R.; Conception, P.; Corma, A.; Fornes, V.; Garcia, H. Angew. Chem., Int. Ed. 2010, 49, 1286.

(13) (a) Gurgiolo, A. E. (Dow Chemical Company). U.S. Patent 4,268,683, 1981. (b) Gurgiolo, A. E. (Dow Chemical Company). U.S. Patent 4,268,684, 1981. (c) Bosetti, A.; Cesti, P.; Cauchi, E.; Prestifilippo, I. U.S. Patent 5,688,988, 1997. (d) Bosetti, A.; Cesti, P.; Calderazzo, F. U.S. Patent 5,698,731, 1997.

(14) (a) Grego, S.; Aricò, F.; Tundo, P. Pure Appl. Chem. 2012, 84, 695. (b) Tundo, P.; Grego, S.; Rigo, M.; Paludetto, R. EP 2-199-278 A1, 2009.

(15) Sun, J.; Yang, B.; Lin, H. Chem. Eng. Technol. 2004, 27, 435.

(16) Liang, M.; Lee, T.-J.; Huang, C.-C.; Lin, K.-Y. J. Chin. Chem. Soc. 2007, 4, 885 .

(17) Wershofen, S.; Klein, S.; Vidal-Ferran, A.; Reixach, E.; Rius-Riuz, F.; EP 2-230-228 A1, 2010.

(18) (a) Guo, X.; Shang, J.; Li, J.; Wang, L.; Ma, Y.; Shi, F.; Deng, Y. Synth. Commun. 2011, 41 (8), 1102. (b) Gupte, S. P.; Shivarkar, A. B.; Chaudhari, R. V. Chem. Commun. 2001, 24, 2620. 